ORIGINAL ARTICLE

\title{
Burnout, psychological morbidity, job satisfaction, and stress: a survey of Canadian hospital based child protection professionals
}

\author{
S Bennett, A Plint, T J Clifford
}

Arch Dis Child 2005;90:1112-1116. doi: 10.1136/adc.2003.048462

See end of article for authors' affiliations ................

Correspondence to: Dr S Bennett, Children's Hospital of Eastern Ontario, 401 Smyth Road, OHtawa, ON K1H 8L1, Canada; Bennett@cheo. on.ca

Accepted 12 January 2005

\begin{abstract}
Aims: (1) To measure the prevalence of burnout, psychological morbidity, job satisfaction, job stress, and consideration of alternate work among multidisciplinary hospital based child and youth protection (CYP) professionals; (2) to understand the relations between these variables; and (3) to understand the reasons for leaving among former programme members.

Methods: Mailed survey of current and former members of all Canadian academic hospital based CYP programmes. Surveys for current members contained validated measures of burnout, psychological morbidity, job satisfaction/stress, and questions about consideration of alternate work. Surveys for former members examined motivation(s) for leaving.

Results: One hundred and twenty six of 165 current members $(76.4 \%)$ and 13/14 (92.9\%) former members responded. Over one third (34.1\%) of respondents exhibited burnout while psychological morbidity was present in $13.5 \%$. Job satisfaction was high, with $68.8 \%$ finding their job "extremely" or "quite" satisfying, whereas $26.2 \%$ found their job "extremely" or "quite" stressful. Psychological morbidity, job satisfaction, and job stress were not associated with any of the demographic variables measured, but burnout was most prevalent among non-physician programme members. Almost two thirds of current members indicated that they had seriously considered a change in work situation. Former members indicated that burnout and high levels of job stress were most responsible for their decision to leave and that increasing the number of programme staff and, consequently, reducing the number of hours worked would have influenced their decision to stay.

Conclusions: Current levels of burnout and the large proportion of individuals who have contemplated leaving the service suggest a potential crisis in Canadian hospital based CYP services.
\end{abstract}

W ith the identification of the battered child syndrome in the early $1960 \mathrm{~s},{ }^{1}$ a major new area of paediatric clinical practice emerged: child abuse and neglect. In response to Kempe's seminal report, the Canadian government initiated provincial mandatory reporting statutes whereby health and social care professionals are required to report suspected child maltreatment to a child welfare agency. ${ }^{2}$ Since Kempe's report, accounts of child maltreatment have soared, both in the USA ${ }^{3}$ and in Canada. ${ }^{4}$ Healthcare professionals in the Canadian province of Ontario report about $9 \%$ of all cases of child maltreatment and of these, hospital based professionals reported $37 \%, 26 \%$, and $36 \%$ of physical abuse, sexual abuse, and neglect cases respectively. ${ }^{5}$

In Canada, there are 16 multidisciplinary child and youth protection (CYP) programmes that are based at paediatric academic health centres. These programmes, which typically consist of paediatricians, social workers, nurses, and administrative assistants, identify, assess, and treat cases of child maltreatment as well as provide expert consultation and assistance in child welfare investigations and management of cases of child maltreatment. ${ }^{2}$ Because all of these programmes are located in urban centres (with catchment areas ranging from one half to three million) and are affiliated with universities/teaching hospitals, many CYP programme members also have academic duties (for example, research, teaching, supervision), in addition to community advocacy and involvement in legal proceedings. ${ }^{2}$

Child maltreatment cases can present challenges for healthcare professionals, particularly those directly involved with the provision of CYP services. Admittedly, many of the stresses to which CYP professionals are exposed are common to all sectors of the healthcare profession. ${ }^{6}$ Nevertheless, there are unique emotional demands placed on CYP practitioners who face concerns for personal safety and possible medico-legal litigation, ${ }^{2-14}$ who are at risk from the cumulative effects of vicarious exposure to trauma ${ }^{10-17}$ and who face stresses when testifying in court. ${ }^{11}$ The lack of central control of child maltreatment cases may result in frustration in dealing with child welfare, law enforcement, and other agencies. These stresses translate to increased reluctance to become involved with CYP. ${ }^{14}{ }^{19}$ Training of paediatricians in child maltreatment work is limited ${ }^{20}$ and an increasing number of leaders in the medical community have stated that paediatricians are inadequately trained to deal with child abuse and neglect. ${ }^{20}$ All of these factors can adversely influence the mental and physical health of CYP professionals, and consequently affect the quality of care provided to patients and their families.

Our study is the first to examine mental health issues and job satisfaction among Canadian hospital based CYP professionals. The specific objectives of this study were to: (1) measure the prevalence of burnout, psychological morbidity, job satisfaction, job stress, and consideration of alternate work situations; (2) understand the relations between these variables; and (3) among those who have left a hospital based CYP team within the past two years, to understand their reasons for leaving.

\section{METHODS}

Study design

This cross-sectional study surveyed current members of all 16 of the dedicated multidisciplinary hospital based CYP 
Table 1 Description of respondents

\begin{tabular}{|c|c|c|}
\hline & Current members & Former members \\
\hline $\mathrm{n}$ & 165 & 14 \\
\hline Response rate & $126(76.4)$ & $13(92.9)$ \\
\hline \multicolumn{3}{|l|}{ Age } \\
\hline$<30$ & $5(4.0)$ & $0(0)$ \\
\hline $30-45$ & $57(45.2)$ & $7(53.8)$ \\
\hline $46-59$ & $60(47.6)$ & $3(23.1)$ \\
\hline $60+$ & $4(3.2)$ & $3(23.1)$ \\
\hline \multicolumn{3}{|l|}{ Marital status } \\
\hline Single/never married & $12(9.5)$ & $1(7.7)$ \\
\hline Married/common-law & $90(71.4)$ & $10(76.9)$ \\
\hline Separated/divorced & 20 (15.9) & $2(15.4)$ \\
\hline Widowed & $4(3.2)$ & $0(0)$ \\
\hline Children at home & $64(50.8)$ & $9(69.2)$ \\
\hline \multicolumn{3}{|l|}{ Occupation } \\
\hline Administrator & $2(1.5)$ & $0(0)$ \\
\hline Nurse & 17 (13.5) & $2(15.4)$ \\
\hline Physician & $46(36.5)$ & $3(23.1)$ \\
\hline Psychologist & $6(4.8)$ & $2(15.4)$ \\
\hline Social worker/child life & $34(27.0)$ & $5(38.5)$ \\
\hline Secretary/researcher & $21(16.7)$ & $1(7.7)$ \\
\hline \multicolumn{3}{|l|}{ Time since school } \\
\hline$<2 y$ & $6(4.8)$ & $0(0)$ \\
\hline $2-5 y$ & $22(17.6)$ & $3(25.0)$ \\
\hline $6-10$ y & 17 (13.5) & $2(16.7)$ \\
\hline$>10 y$ & $80(63.5)$ & $7(58.3)$ \\
\hline \multicolumn{3}{|l|}{ Time in CYP } \\
\hline$<2 y$ & $15(12.0)$ & $0(0)$ \\
\hline $2-5 y$ & $32(25.6)$ & $4(30.8)$ \\
\hline $6-10 y$ & $19(15.2)$ & $3(23.0)$ \\
\hline$>10 y$ & $59(47.2)$ & $6(46.2)$ \\
\hline \multicolumn{3}{|l|}{$\%$ of work week spent in CYP } \\
\hline $1-25 \%$ & $42(33.9)$ & $0(0)$ \\
\hline $26-50 \%$ & 13 (10.5) & $1(7.7)$ \\
\hline $51-75 \%$ & $20(16.1)$ & $3(23.1)$ \\
\hline $76-100 \%$ & $49(39.5)$ & $9(69.2)$ \\
\hline
\end{tabular}

programmes in Canada regarding burnout, psychological morbidity, job satisfaction, job stress, and consideration of alternate work situations. All current members of these programmes, regardless of occupational category or length of service with the programme, were eligible. Former hospital based CYP workers (that is, those who had left one of these programmes within the past two years) were also surveyed. A modified version of Dillman's Tailored Design Survey Method was used for contact and follow up procedures. ${ }^{22}$ This study was approved by the Research Ethics Board of the investigators' hospital.

\section{Survey instruments}

The survey designed for former CYP members solicited information as to the individual's motivation(s) for leaving the programme and what factors, if any, could have prevented their departure. The survey for current CYP members (including programme directors) consisted of the Maslach Burnout Inventory-General Survey (MBI-GS), ${ }^{23}$ the 12-item General Health Questionnaire (GHQ-12), ${ }^{24}$ the Consultants' Mental Health Questionnaire, ${ }^{26}$ and questions regarding demographic characteristics and the frequency with which respondents considered a variety of alternate work situations.

The MBI is the most widely used standardised measure of burnout. ${ }^{23}$ The MBI-General Survey (MBI-GS) consists of 16 items with each of the three components of burnout (exhaustion, cynicism, professional efficacy) measured on separate Likert-type subscales. The total score for each subscale is classified as low, moderate, or high according to predetermined cut-off points (based on normative data from a North American sample). Internal consistency, test-retest reliability, convergent validity, and discriminant validity have all been established. ${ }^{23}$

The GHQ- $12^{24}$ was used to assess the point prevalence of psychological morbidity in the study sample. Covering four identifiable elements of distress (depression, anxiety, social impairment, hypochondriasis), the GHQ-12 is a valid and reliable self-administered screening tool that has been designed to detect current diagnosable psychological disorders in community samples and occupational settings. ${ }^{25}$ The 12 items on the GHQ are rated according to whether they have been experienced "not at all", "the same as usual", "rather more than usual", or "much more than usual" in the past few weeks. Each item is scored 0 ("not at all/same as usual") or 1 ("rather more than usual/much more than usual"), giving a maximum score of 12. A score of 4 or more identifies respondents who are experiencing psychological morbidity. Test-retest reliability after six months is noted to range between 0.75 and 0.90 . Internal consistency estimates include 0.83 for split-half reliability, while alpha coefficients are cited as $0.82-0.90 .^{25}$

The Consultants' Mental Health Questionnaire ${ }^{26}$ has been widely used in many healthcare settings to measure the constructs of job satisfaction and job stress. ${ }^{27-32}$ For this study, items were slightly modified to increase relevance to all CYP professionals, not just physicians. It includes 25 specific sources of stress and 17 specific sources of satisfaction that respondents are asked to rate on a four point scale $(0=$ "not at all," $1=$ "sometimes," $2=$ "quite a bit," $3=$ "a lot"). In addition, respondents were also asked to provide global ratings of job stress and satisfaction, reflected on a scale ranging from 1 to 5 .

The survey also solicited information on gender, age, family structure, occupational category, time since highest degree, length of service in CYP, percentage of work week spent in CYP, and whether shiftwork was required. A final section asked respondents to indicate whether they had considered four alternate work situations.

\section{Data entry and analysis}

Data entry and analysis were performed using the SPSS-PC version 11.0.1 statistical package (SPSS; Cary, NC). Descriptive statistics are presented for overall burnout as

Table 2 Prevalence of burnout, psychological morbidity, job stress, and job satisfaction among current hospital based CYP professionals

\begin{tabular}{lc}
\hline $\mathbf{n}=126$ & $\mathbf{n}(\%)$ \\
\hline Burnout* & $43(34.1)$ \\
High emotional exhaustion & $29(23.0)$ \\
High cynicism & $27(21.4)$ \\
Low professional efficacy & $20(15.9)$ \\
Psychological morbidity† & $17(13.5)$ \\
Job satisfactionł§ & \\
Extremely satisfying & $19(15.2)$ \\
Quite satisfying & $67(53.6)$ \\
Somewhat satisfying & $30(24.0)$ \\
Minimally satisfying & $9(7.2)$ \\
Not at all satisfying & $0(0.0)$ \\
Job stressł & $2(1.6)$ \\
Extremely stressful & $31(24.6)$ \\
Quite stressful & $56(44.4)$ \\
Somewhat stressful & $32(25.4)$ \\
Minimally stressful & $5(4.0)$ \\
Not at all stressful &
\end{tabular}

*As measured by the MBI-GS. ${ }^{23}$

†As indicated by a score $\geqslant 4$ on the GHQ-12. ${ }^{24} 2531$

$\ddagger$ As measured by the Consultants' Mental Health Questionnaire. ${ }^{26}$

$\S$ Total may not sum to 126 because of missing data. 
well as its three components, ${ }^{23}$ psychological morbidity, ${ }^{24}$ and overall job satisfaction and job stress. ${ }^{26}$ Differences in the prevalence of burnout, psychological morbidity, and overall job satisfaction and job stress according to various demographic groups were assessed using Mantel-Haenszel $\chi^{2}$ tests with Yates's correction or Fisher's exact test, where appropriate.

The Pearson product moment correlation coefficient was used to examine the relation between individual components on the job satisfaction questionnaire and overall satisfaction, and individual components on the job stress questionnaire and overall stress. High levels of overall satisfaction and overall stress were defined as a score of 3 or more on the respective global satisfaction and stress items. Logistic regression, using a backward stepwise procedure, modelled factors independently associated with the consideration of alternate work situations. In this case, marital status, respondents' age, presence of children at home, length of time in CYP, percentage of work week spent in CYP, overall job satisfaction, overall job stress, psychological morbidity, and each of the three components of burnout (exhaustion, cynicism, professional efficacy) were eligible for inclusion in the model. The significance level (alpha) for variable selection was set at 0.10 for both entry and exit. ${ }^{33}$ Regression results are expressed in terms of adjusted odds ratios and $95 \%$ confidence intervals.

\section{RESULTS}

\section{Respondents}

Among the 16 programmes, 179 eligible participants were identified and $139(77.7 \%)$ returned completed surveys. Table 1 provides further descriptions of the sample.

\section{Mental health indicators, job satisfaction, and job stress}

Table 2 describes the levels of burnout, psychological morbidity, job satisfaction, and job stress reported by the respondents. Over one third $(34.1 \%)$ of respondents exhibited burnout (defined as high levels of emotional exhaustion and/ or high levels of cynicism and/or low levels of professional efficacy) while psychological morbidity was present in $13.5 \%$. Job satisfaction was high, with $68.8 \%$ finding their job "extremely" or "quite" satisfying, whereas $26.2 \%$ found their job "extremely" or "quite" stressful.

Overall burnout was significantly associated with respondents' job category, with more than $40 \%$ of social workers and psychologists being categorised as burned out, relative to less than one third of physicians $(\mathrm{p}<0.005$, MantelHaenszel $\chi^{2}$ ). When the three components of burnout were scrutinised, only the professional efficacy subscale was found to be associated with any measured demographic variables, with the lowest levels of professional efficacy seen among the non-physicians in the CYP programmes $(\mathrm{p}<0.001)$.

Psychological morbidity and overall levels of job satisfaction and job stress were not associated with any of the

Table 3 Consideration of alternate work situations

\begin{tabular}{ll}
\hline $\mathbf{n}=124$ & $\mathbf{n}(\%)$ \\
\hline Any change* & $78(62.9)$ \\
Leaving for position outside CYP & $42(33.9)$ \\
Leaving for a job outside hospital setting & $38(30.6)$ \\
Reducing hours worked & $63(50.8)$ \\
Taking early retirement & $28(22.8)$ \\
Have taken leave of absence in past & $17(13.7)$ \\
\hline
\end{tabular}

*Defined as consideration of leaving current position with hospital based CYP for a position outside CYP and/or for a position outside the hospital setting and/or reducing hours worked and/or taking early retirement and/or requesting a leave of absence. demographic variables measured. Overall satisfaction was most strongly correlated with having a high level of responsibility $(r=0.352)$ and being perceived to do the job well by colleagues $(r=0.264)$. On the other hand, overall stress was most highly correlated with having conflicting demands on respondents' time $(r=0.545)$, having too great an overall volume of work $(r=0.520)$, having inadequate staff to do their job properly $(r=0.498)$, having their home life disrupted because of spending long hours at work $(r=0.471)$, feeling under pressure to meet deadlines $(r=0.438)$, being involved with the emotional distress of patients $(r=0.413)$, and uncertainty over the future funding of their unit/programme $(r=0.402)$.

\section{Consideration of alternate work situations}

The proportion of respondents who responded affirmatively to having considered various alternate work situations is presented in table 3. Almost two thirds of Canadian hospital based CYP professionals have contemplated some form of change, with half reporting that they had considered reducing the number of hours worked in the programme, and approximately one third noting that they had given thought to leaving the programme.

In the multivariable model (table 4), predictors of respondents' consideration of any alternate work situation included increased proportion of work week spent in CYP, higher levels of psychological morbidity, and being a physician or a secretary/researcher. Those who reported high levels of cynicism (one of the components of burnout) were more than three times as likely to have given thought to some form of alternate work situation. Importantly, high levels of overall job satisfaction were protective, with greater than $50 \%$ reduction in the "risk" of considering leaving among those who reported their job to be "quite" or "extremely" satisfying.

\section{Former members}

Among respondents who had left a Canadian hospital based CYP programme within two years preceding survey administration, more than half $(7 / 13,53.8 \%)$ had been gone from the programme for one year or more. When asked to reflect on their time with their programme, the majority reported high levels of job satisfaction; the proportions were similar to that reported by current staff, with $46.2 \%$ and $23.1 \%$ reporting that their jobs were "quite" and "extremely" satisfying respectively. On the other hand, levels of job stress reported among former staff were higher than those reported by current members, though this did not differ statistically.

\begin{tabular}{|c|c|c|}
\hline & $\mathrm{AOR}^{*}$ & $95 \% \mathrm{Cl}$ \\
\hline \multicolumn{3}{|l|}{ \% of work week spent in CYP } \\
\hline$<25 \%$ & 1.00 & Reference \\
\hline $26-75 \%$ & 1.57 & 0.39 to 6.36 \\
\hline$>75 \%$ & 3.49 & 1.15 to 10.67 \\
\hline High overall job satisfaction $†$ & 0.48 & 0.24 to 0.97 \\
\hline Psychological morbidity $\ddagger$ & 6.77 & 0.69 to 65.84 \\
\hline \multicolumn{3}{|l|}{ Occupation } \\
\hline Administrator & 1.00 & Reference \\
\hline Nurse & 0.27 & 0.01 to 7.48 \\
\hline Physician & 3.34 & 0.14 to 77.22 \\
\hline Psychologist & 0.11 & 0.002 to 5.50 \\
\hline Social worker & 0.69 & 0.03 to 16.89 \\
\hline Secretary/research assistant & 1.21 & 0.05 to 29.74 \\
\hline High cynicism on $\mathrm{MBI}$ & 3.19 & 1.50 to 6.78 \\
\hline
\end{tabular}

*Adjusted for all variables listed in table.

tIndicated by global rating of "quite" or "extremely" satisfying \#lndicated by score of $\geqslant 4$ on GHQ-12. 


\section{What is already known on this topic}

- High levels of burnout and job turnover are well documented in front line community social workers since the 1980s

- Surveys among paediatricians have revealed child abuse work as a job stress

For example, 38.5\% reported their job with CYP to have been "quite" stressful, with another $7.7 \%$ reporting "extreme" stress.

Most former staff noted that their decision to leave hospital based CYP was not made impulsively, with more than three quarters having contemplated the decision for more than six months. The reasons most frequently cited for leaving included job stress and feelings of burnout (38.5\%) as well as concerns for family life (30.8\%). Many former staff $(38.5 \%)$ reported that nothing could have made them stay with their position in CYP. Among those who felt their decision could have been influenced by change, the most frequently noted suggestions were to reduce the number of hours worked and to increase the number of programme staff.

\section{DISCUSSION}

Only within the past 15 years has serious attention been paid to professionals' personal reactions to working with maltreated children. ${ }^{7-19}$ The sequelae of these reactions are exemplified in a recent UK report that suggests many are reluctant to undertake child protection work and that, as a result, $30 \%$ of child protection positions are unfilled. ${ }^{14}$

Our study, which is the first comprehensive examination of Canadian hospital based multidisciplinary CYP professionals' experiences, supports the concern that these practitioners are experiencing high levels of burnout and job stress and that, consequently, many have considered changing their work arrangements. Admittedly, our findings may not generalise to jurisdictions that differ in mandate and/or provision of services; however, the internal validity of our study is quite high, due to its census approach (whereby every member of every hospital based CP programme in Canada was invited to participate), use of validated instruments, and high response rate. This allows a high degree of confidence in the study's findings.

These findings are disturbing, particularly in such a demanding and highly specialised area of practice in which there are few formal training opportunities and where qualified individuals are already in short supply. ${ }^{212} 142021$ In our study, $38.5 \%$ of former hospital based CYP professionals indicated that job stress and perceived burnout were important factors in their decision to leave the programme. This, along with the observation that more than one third of current CYP practitioners are burnt out and that almost two thirds have contemplated alternate work situations, suggest that a crisis may be pending at hospital based CYP programmes in Canada. Given the crucial role played by hospital CYP professionals in ensuring the care and safety of maltreated children, such a crisis could be particularly tragic.

A number of studies have examined these same constructs among community child welfare social workers ${ }^{7-10}$ 34-35 and other hospital based specialties. ${ }^{27-32}{ }^{36-39}$ Only the work by Grunfeld and colleagues $^{31}$ presents a Canadian, hospital based multidisciplinary perspective; however, direct comparison of our results with the cancer care workers in the study of Grunfeld et al is precluded because the study population also included community based respondents. Furthermore,

\section{What this study adds}

- This study shows that, similar to community based professions, there are high levels of burnout and job stress but interestingly, high levels of job satisfaction

- Results suggest an impending exodus of child protection professionals and a crisis in hospital based services for maltreated children and youths

comparisons between specialties are not fruitful because the objective of this study was not to determine whether Canadian hospital based CYP practitioners are better or worse off than practitioners in other disciplines. Rather, because the study used standardised, validated instruments whose outcome categories have been "benchmarked" against various cultural and occupational groups, the findings stand alone and do not require a comparison group to be put in context. Nevertheless, researchers in other jurisdictions are encouraged to repeat our study so as to inform international comparisons vis-à-vis the state of child protection.

Current and former members of the Canadian hospital based CYP programmes highlighted the need for increased staff in order to strengthen the multidisciplinary programmes and make workloads more manageable, thereby reducing stress. Appropriate compensation for the additional time needed to conduct assessments of suspected child abuse has also been suggested. ${ }^{2}$ Nonetheless, increased, dedicated funding for these programmes is only part of the solution. Undergraduate and/or postgraduate specialist training should be a requirement for all professionals who work as part of these programmes, while in-services and/or continuing education in child abuse and neglect should also be made available to any health professional who works with children. $^{2021}$ Furthermore, if steps are to be taken to improve the situation among this occupational group (for example, employee assistance programmes), these, too, must be evaluated. Yet, because hospital based child protection is but one component of a system that also includes community based agencies, law enforcement, the justice system, government, and the public-at-large, any remedial actions must take into account the entire system. These tasks are monumental but not insurmountable; the children are counting on us.

\section{ACKNOWLEDGEMENTS}

This study was funded by the Children's Hospital of Eastern Ontario Research Institute. Dr Plint is supported by a Junior Investigator Award from the CHEO Research Institute. The authors wish to express their gratitude to the participants who found time to complete this emotionally-demanding survey.

\section{Authors' affiliations}

S Bennett, A Plint, Department of Pediatrics and of Psychiatry, University of Ottawa, Canada

T J Clifford, Department of Pediatrics and of Community Medicine and Epidemiology, University of Ottawa, Canada

Competing interests: none declared

\section{REFERENCES}

1 Kempe C. The battered child syndrome. JAMA 1962;181:17-24.

2 Loo S. Child abuse: reporting and classification in health care settings, 1999 www.hc-sc.gc.ca/hppb/familyviolence/pdfs/eng_health_care_reporting.pdf (accessed 17 November 2004).

3 Sedlak AJ, Broadhurst DD. Third national incidence study of child abuse and neglect: final report. Washington, DC: US Department of Health and Human Services, 1996, http://nccanch.acf.hhs.gov/pubs/statsinfo/nis3.cfm (accessed 17 November 2004) 
4 Trocme N, MacLaurin B, Fallon B, et al. Child maltreatment in Canada: Canadian incidence study of reported child abuse and neglect. H49-151/ 2000E. Ottawa: Minister of Public Works and Government Services, 2001 http://www.phac-aspc.gc.ca/publicat/cissr-ecirc/ (accessed 11 November 2004).

5 Trocme N, McPhee D, Tam KK. Child abuse and neglect in Ontario: incidence and characteristics. Child Welfare 1995;74:563-86.

6 Koehoorn M, Lowe GS, Rondeau KV, et al. Creating high-quality health care workplaces. W/14. 23-1-2002. CPRN Discussion Paper. Ottawa: Canadian Policy Research Networks, http://www.cprn.com/en/doc.cfm?doc $=55$ (accessed 11 November 2004)

7 Guterman N. A responsibility at risk: perceptions of stress, control and professional effectiveness in child welfare direct practitioners. J Soc Serv Rev 1994;20:99-120.

8 Fryer GE, Miyoshi TJ. The relationship of child protection worker attitudes to attrition from the field. Child Abuse Negl 1989;13:345-50.

9 Anderson DG. Coping strategies and burnout among veteran child protection workers. Child Abuse Negl 2000;24:839-48.

10 Regehr C. Stressors in child welfare practice. OACAS Journal 2000;44:2-4

11 Johnson CF. Child abuse as a stressor of pediatricians. Pediatr Emerg Care 1999;15:84-9.

12 Lally K. In search of specialists to care for abused children. Children's Hospitals Today Winter, 2002:9-11.

13 Azar S. Preventing burnout in professionals and paraprofessionals who work with child abuse and neglect cases: a cognitive behavioral approach to supervision. J Clin Psychol 2000;56:643-63.

14 Dyer 0 . Doctors reluctant to work on child protection committees, survey shows. BMU 2004;328:307.

15 Stoler LR. Researching childhood sexual abuse: anticipating effects on the researcher. Fem Psychol 2002;12:269-74.

16 McCann IL, Pearlman LA. Vicarious traumatization: a framework for understanding the psychological effects of working with victims. J Trauma Stress 1990;3:131-49.

17 Lyon $\mathrm{E}$. Hospital staff reactions to accounts by survivors of childhood abuse. Am J Orthopsychiatry 1993;63:410-16

18 Kinard EM. Conducting research on child maltreatment: effects on researchers. Violence Vict 1996;11:65-9.

19 Hall D. Protecting children, supporting professionals. Arch Dis Child 2003;88:557-9.

20 Ward MG, Bennett S, Plint AC, et al. Child protection: a neglected area of pediatric residency training. Child Abuse Negl 2004;28:1113-22.
21 Bannon MJ, Carter YH. Paediatricians and child protection: the need for effective education and training. Arch Dis Child 2003;88:560-2.

22 Dillman D. Mail and internet surveys: the tailored design method. New York: John Wiley and Sons, 2000.

23 Maslach C Jackson SE, Leiter MP. Maslach Burnout Inventory Manual, 3rd edition. Palo Alto, CA: Consulting Psychologists Press, 1996.

24 Goldberg D. A user's guide to the General Health Questionnaire. Windsor: NFER-Nelson Publishing, 1988

25 McDowell I, Newell C. Psychological well-being. In: McDowell I, Newell C, eds. Measuring health: a guide to rating scales and questionnaires. New York: Oxford University Press, 1996:177-237.

26 Graham J, Ramirez AJ, Cull A, et al. A user's guide to the Consultants' Mental Health Questionnaire 1996.

27 Graham J, Ramirez AJ, Cull A, et al. Job stress and satisfaction among palliative physicians. Palliat Med 1996;10:185-94.

28 Graham J, Ramirez AJ, Field S, et al. Job stress and satisfaction among clinical radiologists. Clin Radiol 2000;55:182-5.

29 Ramirez AJ, Graham J, Richards MA, et al. Burnout and psychiatric disorder among cancer clinicians. Br J Cancer 1995:71:1263-9.

30 Ramirez AJ, Graham J, Richards MA, et al. Mental health of hospital consultants: the effects of stress and satisfaction at work. Lancet 1996;347:724-8

31 Grunfeld E, Whelan TJ, Zitzelsberger L, et al. Cancer care workers in Ontario: prevalence of burnout, job stress and job satisfaction. CMAJ 2000;163:166-9.

32 Visser MRM, Smets EMA, Oort FJ, et al. Stress, satisfaction and burnout among Dutch medical specialists. CMAJ 2003;168:271-5.

33 Mickey RM, Greenland S. The impact of confounder selection criteria on effect estimation. Am J Epidemiol 1989;129:125-37.

34 Harrison WD. Role strain and burnout in child-protective service workers. Soc Serv Rev March, 1980:31-44.

35 Winefield HR, Barlow JA. Client and worker satisfaction in a child protection agency. Child Abuse Negl 1995;19:897-905.

36 Papadatou D, Anagnostopoulos F, Monos D. Factors contributing to the development of burnout in oncology nursing. Br J Med Psychol 1994;67:187-99.

37 Lloyd S. Burnout, depression, life and job satisfaction among Canadian emergency physicians. J Emerg Med 1994; 12:559-65.

38 Oehler JM, Davidson MG, Starr LE, et al. Burnout, job stress, anxiety and perceived social support in neonatal nurses. Heart Lung 1991;20:500-5.

39 Stechmiller JK, Yarandi HN. Predictors of burnout in critical care nurses. Heart Lung 1993;13:534-41. 